\title{
A política como (des)construção de sujeitos: desencaixes e rearticulações identitárias em protestos multitudinários contemporâneos ${ }^{1}$
}

\author{
Angela Cristina Salgueiro Marques \\ Ricardo Fabrino Mendonça' \\ I - UFMG \\ Belo Horizonte (MG), Brasil
}

Resumo: Este artigo busca pensar a política a partir de processos de constituição de sujeitos, em uma sistematização que abrange dimensões éticas, estéticas, comunicacionais e políticas dos modos de agência dos indivíduos. Interessa-nos contestar concepções que entendem o sujeito como constituído anteriormente à luta política ou como irrelevante para a compreensão dessa luta. Na abordagem aqui delineada, a política (assim como suas descontinuidades e rupturas) emerge no próprio processo de desconstrução/deslocamento de sujeitos. Para fazer tal discussão, o texto relê, criticamente, quatro propostas distintas no âmbito da teoria política contemporânea em sua interface com a comunicação: (1) as discussões de Laclau e Mouffe sobre o conceito de articulação; (2) os debates sobre desidentificação e subjetivação em Jacques Rancière; (3) a discussão de Judith Butler sobre sujeito; e (4) a crítica de Patchen Markell à teoria do reconhecimento a partir da defesa da precedência da ação sobre as identidades. Na sequência, a ideia fundamental a atravessar esses autores e autoras será mobilizada em uma breve ilustração de seu potencial heurístico para a leitura de fenômenos empíricos. Abordaremos como essa atenção à desconstrução de sujeitos políticos joga luzes importantes sobre protestos multitudinários contemporâneos.

Palavras-chave: sujeito político; desidentificação; protestos multitudinários.

Abstract: The politics as (de)construction of subjects: identity dislocations and rearticulations in contemporary multitudinal protests - The aim of this paper is to think politics as processes

1 Uma primeira versão deste texto foi apresentada no $40^{\circ}$ Encontro Anual da Anpocs, 2016. Somos gratos aos participantes do ST 11 "Dinâmicas subjetivas e espaço público: gramáticas emocionais, corporais e estéticas", pelas observações que nos permitiram aprimorar e clarear nosso argumento. O trabalho é fruto de pesquisa financiada pelo CNPq e pela FAPEMIG. 
of citizens' constitution, in a theoretical systematization that consider ethical, aesthetical, communicational and political dimensions of individual's modes of agency. We contest conceptions that understand subjects as constituted previously to the political struggle or as irrelevant for the understanding of this fight. We argue that politics (as well as its discontinuities and ruptures) emerges in the process of deconstruction/displacement of subjects. In order to build our argument, the text critically revisit four distinct proposals in the scope of contemporary political theory in its interface with communication theory: (1) the discussions of Laclau and Mouffe on the concept of articulation; (2) the debates on de-identification and subjectification in Jacques Rancière; (3) the discussion of Judith Butler on subject; and (4) the critics of Patchen Markell to the theory of the recognition from the defense of the anteriority of the action on the identities construction. At the end, the basic idea to crisscross these authors will be mobilized in one brief illustration of its heuristic potential for the analysis of empirical phenomena. We will argue that this attention to the deconstruction of political citizens shed light on contemporary multitudinal protests.

Keywords: political subject; de-identification; contemporary multitudinal protests.

\section{Introdução}

Este artigo propõe-se a discutir a centralidade do processo de desconstrução de sujeitos para a política, evidenciando como essa visão tem ganhado força em correntes teóricas bastante distintas. Tal esforço se justifica porque, histórica e muito frequentemente, a política é pensada como uma construção coletiva feita por sujeitos e/ou ultrapassando o particularismo desses sujeitos. É o que se observa, por exemplo, nas premissas a embasar o trabalho de diferentes contratualistas: o espaço da política partiria do pressuposto de sujeitos existentes e possibilitaria a estruturação de alguma espécie de coletividade que transcende tais existências. Essa visão também aparece em algumas vertentes preocupadas em entender processos de agregação de preferências, jogos de força entre atores diversos e lutas sociais conduzidas publicamente.

Interessa-nos, aqui, contestar concepções teóricas que entendem o sujeito como ente constituído anteriormente à política. O processo de formação de subjetividades não é pré-político, mas base importante para a compreensão da própria política. Isso por dois motivos fundamentais. Em primeiro lugar, porque os sujeitos são atravessados por forças, assimetrias, disputas e agenciamentos de bases diversas ao longo de sua formação. Em segundo lugar, porque a própria reconfiguração processual e interacional dos sujeitos é a manifestação política do processo por meio do qual sociedades se transformam em meio a seus conflitos e disputas. Sujeitos não são o a priori ou um efeito da política. É mais adequado pensá-los como meio de manifestação concreto e corpóreo da prática da política. Entendemos a política, portanto, como prática comunicacional e conflitiva de constituição e redefinição constante de sujeitos, suas ações e formas de agenciamento.

É nesse sentido que nos interessa chamar a atenção para as rupturas e momentos de deslocamento/desconstrução que atravessam a prática política. Se o processo de formação 
de sujeitos é um processo contínuo de permanente "tornar-se", de progressivas conexões ordenadas que se aprimoram sem cessar, é preciso prestar mais atenção aos hiatos, desencaixes e desconexões, que o atravessam e o impulsionam. É muito recorrente focar a discussão sobre formação de sujeito na ideia de produção de uma narrativa que dota um todo descontínuo de coerência, a partir de progressivas conexões que vão adicionando complexidade ao processo. Nosso intuito é dirigir o foco, desde uma visada conceitual e comunicacional, para essa desconexão intrínseca ao próprio re-narrar de identidades. Como em um quebra-cabeça, processos identitários envolvem tentativas de encaixe, sendo relevantes os momentos em que os desencaixes evidenciam a desarticulação de um todo, alterando a configuração do jogo.

Para delinear tal argumento, recorreremos a alguns autores-chave de diferentes matrizes contemporâneas da teoria política e da teoria da comunicação. Laclau e Mouffe, Rancière e Butler permitem, por diferentes caminhos, uma articulação entre bases foucaultianas e debates pós-estruturalistas que acaba por evidenciar a centralidade do processo de desconstrução de sujeitos para a teoria política em sua interface com a comunicação. Markell, por sua vez, parte de bases hegelianas, da teoria crítica e de um diálogo com autores preocupados com o espaço público para salientar a precedência da ação sobre a identidade. Em todos eles, nota-se que o sujeito político é abordado como resultado de um processo de distanciamento - uma espécie de "sair de si" - na medida em que é o questionamento de identificações que alimenta processos de formação de sujeitos. Além disso, o sujeito político ganha seus contornos na relação comunicativa, por meio da qual experiências criadoras constituem fundamento essencial para a autonomia e emancipação, e na qual lutas políticas são vividas tanto do ponto de vista coletivo quanto individual, uma vez que as interações são, em maior ou menor medida, baseadas em relações de poder.

Feita essa discussão, o artigo conclui com uma breve ilustração de seu potencial para a leitura de fenômenos empíricos. Abordaremos como essa atenção à desconstrução de sujeitos políticos joga luzes importantes sobre protestos multitudinários contemporâneos.

\section{O processo de configuração de sujeitos como prática relacional de articulação}

Iniciamos nosso percurso teórico pela clássica discussão de Laclau e Mouffe (2001 [1985]) sobre hegemonia que é, essencialmente, uma tese sobre a processualidade da formação dos sujeitos no cerne da política. Todo o esforço que realizam em meados da década de 1980 para pensar a encruzilhada pela qual passava a esquerda envolve uma reconceituação sobre o processo de configuração dos atores políticos, evidenciando que é o próprio movimento de construção (e desconstrução) de tais atores que alimenta a prática política. Laclau e Mouffe argumentaram, naquele momento, que a ascensão de novas lutas 
emancipatórias (como as do feminismo, as de movimentos étnicos e as de minorias sexuais) colocava não apenas novas questões na cena de conflitos públicos, mas deslocava a cena desses conflitos, alterando a compreensão do sujeito político revolucionário. O futuro da esquerda passava por uma desconstrução identitária, que viabilizaria a construção de outras formas revolucionárias de identificação.

Laclau e Mouffe (2001) afirmam que o proletário não é a fonte nem a consequência de um processo político, mas emerge como a manifestação disruptiva do político. Justamente por isso "o proletário" ou "a classe trabalhadora" não está pronto e estabelecido, nem tem missão e destino pré-fixados. Trata-se de uma processualidade que surge na luta ao mesmo tempo em que a impulsiona. É nesse sentido que recusam as ideias de classe e de subjetividade como tradicionalmente concebidas pelo marxismo. ${ }^{2}$ É também nesse sentido que autor e autora defendem que a esquerda precisaria se reconfigurar naquele momento histórico, incorporando uma diversidade de agências que deslocavam contextos, compreensões e subjetividades da luta emancipatória.

Para compreender a base conceitual dessa proposta e avançar na compreensão da dimensão disruptiva que atravessa a formação de sujeitos políticos, é importante discutir a noção e articulação, como trabalhada por eles. Na visão de Laclau e Mouffe, articulação é "qualquer prática de estabelecimento de uma relação entre elementos de modo que a identidade deles é modificada pela prática articulatória" (2001, p. 105). A articulação não é, pois, uma simples ligação entre elementos pré-constituídos. Ao contrário, trata-se de uma relação, sempre contingente, que modifica os elementos por ela vinculados, sempre implicando uma ruptura com formas articulatórias precedentes. Com isso, eles chamam a atenção para a centralidade da relação na definição dos elementos articulados por essa mesma relação. Se tais entidades fossem "absolutamente externas umas às outras, elas teriam que ser totalmente internas a si mesmas" (LACLAU \& MOUFFE, 2001, p. 111).

Elementos são pensados, abstratamente, como diferenças não articuladas. Discurso, por sua vez, é o nome dado à totalidade estruturada que surge do processo da prática articulatória. São os discursos, entendidos de forma muito concreta por Laclau e Mouffe, que dotam elementos de sentido (e substância, poder-se-ia dizer) por meio de articulações. Discursos esses que são sempre metafóricos, dada a impossibilidade de um encaixe perfeito que encerre as possibilidades de escape e deslocamento da significação.

Nos quadros deste argumento, se os elementos são precários e redefinidos pelas articulações que os constituem, a contingência torna-se central para a compreensão do mundo e de suas dinâmicas. Na visão de autor e autora, o antagonismo, base da política, reside justamente em uma espécie de exposição da contingência. Ele nasce da negação de uma ordem estabelecida, expondo seus limites e contestando suas tramas articulatórias. Essa contestação é o que permite transformar entidades que compõem dado discurso em elementos, remetendo-os a outras possibilidades de articulação.

2 Embora eles encontrem interessantes diálogos parciais entre suas ideias e a de autores como Rosa Luxemburgo, Sorel e Gramsci. 
É aqui que a discussão sobre a formação de sujeito emerge de forma eloquente no trabalho de Laclau e Mouffe. O antagonismo político depende de um tipo de deslocamento que retira o sujeito, ainda que efemeramente, da trama articulatória em que se insere para abrir-lhe outras possibilidades de articulação. É nesse hiato, nessa decalagem, que a contingência do mundo e dos sujeitos se revela em sua potência política e também estética. O processo de configuração de sujeitos, fruto da articulação de posições de sujeito no bojo de uma multiplicidade de relações sociais, tem um quê de imprevisibilidade na medida em que escapa aos determinismos e sentidos pré-estabelecidos. Ele emerge da ruptura, da experimentação, da recusa e da reorganização que a acompanha. É a negação de articulações existentes que devolve os sujeitos à condição de elementos reconfiguráveis, modeláveis, no seio de outras articulações possíveis.

De forma sintética: o processo de formação de sujeitos é atravessado por fixações parciais e deslocamentos, que revelam (e impulsionam) movimentos agonísticos contínuos de transformação das articulações que definem os discursos existentes e as entidades que os compõem. Quando sujeitos se tornam elementos, no sentido dado ao termo por Laclau e Mouffe, abrem-se processos de ressignificação dos discursos/ordens existentes. Por meio dessa reinvenção - desse processo disruptivo de deslocamento de articulações - manifesta-se a política, como prática de rearticulação de relações em campos de antagonismos intersectantes.

Movendo-se do plano mais abstrato para o mais aplicado, Laclau e Mouffe (2001) operacionalizam tais ideias para realizar um diagnóstico crítico dos anos 1980, explorando seus potenciais. A esquerda dos anos 1980, segundo eles, precisava deslocar a categoria unificadora do proletariado, para promover outras articulações e identificações (e sujeitos) críticos. A experiência da democracia deveria consistir no reconhecimento da multiplicidade das lógicas sociais e da necessidade de produção de outras articulações (inclusive e, principalmente, as articulações comunicacionais), que possibilitem a construção/emersão de antagonismos deslocadores. Tais articulações abrigam, necessariamente, as bases para a expressão de novos sujeitos, inexistentes em outros contextos articulatórios. Assim, a pluralidade, as interações, o deslocamento e a indeterminação são pilares sobre os quais se assentaria um imaginário político democrático e libertário.

\section{A desidentificação e as cenas de dissenso em Jacques Rancière}

O próximo passo de nosso percurso teórico é o trabalho de Jacques Rancière, para quem a política está fortemente articulada a processos de subjetivação e configuração de um sujeito político. A concepção de sujeito político que Jacques Rancière (2010, 2014) nos apresenta está intrinsecamente ligada à ação de verificação da pretensa igualdade fixada nas leis e instituições. A questão central da subjetivação política para Rancière está na concepção do ato de interlocução e de suas condições e discursos, que tecem 
linhas de força e lugares de sujeito que a eles impõe nome, pertencimento e ocupação. Nesse sentido, ele define três facetas importantes do processo de subjetivação: a) a demonstração argumentativa de um dano original (divisão entre aqueles que devem governar e aqueles que devem se submeter ao governo) e seu tratamento através da verificação constante do estatuto dos interlocutores (não atendimento ao pressuposto da igualdade); b) a dramatização performática na cena de dissenso; e c) a desidentificação com uma identidade atribuída pela ordem policial. É exatamente este o ponto que nos interessa: processos de subjetivação nascem de rupturas que deslocam os sujeitos das posições em que estariam previamente encaixados, instaurando cenas dissensuais.

Essa situação de mise en scène constitui, para Rancière (2010), a base estética da ação política e da concomitante criação dos sujeitos como interlocutores: certos sujeitos que não contam criam uma cena polêmica comum na qual colocam em discussão o status do que é dado e impõem exame e discussão dessas coisas que não eram visíveis ou consideradas anteriormente. Na cena de dissenso, estão em jogo, sobretudo, formas desiguais de distribuição da palavra e o questionamento dos modos de produção e circulação de discursos (LELO \& MARQUES, 2014).

A verificação da igualdade nessas cenas só é possível, segundo Rancière, quando há dissenso entre duas formas distintas de dividir e compartilhar temporalidades, "dizibilidades" e corporalidades: uma, consensual, que afirma a ausência de vazios, hiatos ou descompassos entre o já dado e o existente; e outra, dissensual, que afirma a presença de excessos, do suplemento, da ausência de encaixe perfeito entre corpos, espaços, tempos e palavras. A evidência da constante tensão entre essas formas de partilha do sensível fica a cargo daqueles que Rancière $(2011,2010)$ chama de sem-parte. Os sem-parte são o resultado de um processo de desidentificação, evidenciando a conta sempre mal feita entre aqueles que podem (e aqueles que não podem) falar, governar, participar da gestão da sociedade. Eles não se confundem propriamente com indivíduos ou com um "grupo de interesses ou ideias" (muito embora Rancière se refira aos operários como sem-parte), mas são uma metáfora para designar um dispositivo particular de subjetivação e de litígio por meio do qual a política passa a existir como forma de disjunção. Entretanto, enquanto, por exemplo, a subjetivação foucaultiana aponta para a produção de um sujeito ético (considerando os procedimentos por meio dos quais um indivíduo se apropria de si, transformando-se em sujeito de suas próprias práticas), a subjetivação em Rancière (2014) aponta não para a produção de identidades, mas para o questionamento da disciplinarização e das perspectivas identitárias. Nesse sentido, a desidentificação é uma noção que tenta organizar processos emancipatórios a partir de uma desclassificação das coordenadas que reproduzem a ordem social.

Não se trata, portanto, de renunciar à noção de identidade, mas de pensar o conceito de sujeito como lugar provisório de união, um nome desidentificado que marca, ao mesmo tempo, os horizontes desses mundos possíveis e os contornos de forças políticas 
dissensuais que se cruzam e produzem um movimento, um gesto de questionamento da ordem. Interessa a Rancière o sujeito desidentificado, rebelde e móvel sob o qual se juntam as forças políticas de ruptura e dinsjunção.

Para Rancière não se trata de pensar um distanciamento dos indivíduos em relação a si mesmos. A identidade policial não designa uma relação consigo, um modo de existência ou uma modalidade constitutiva do ser social: ela designa simplesmente o conjunto de instituições, leis, normas, regras e códigos que determinam possibilidades consensuais de vida ligadas à posição social. A desidentificação de Rancière não opera um distanciamento/hiato com relação a mim mesmo, mas à ordem policial que me designa uma posição e determina minhas possibilidades (FJELD \& TASSIN, 2015, p. 210):

\begin{abstract}
A subjetivação em Rancière procura problematizar o processo de construção de um sujeito plural, coletivo, não identitário e não associado a comunidades ligadas por classe, raça, sexo ou profissão. Essa subjetivação desidentificatória é um processo de produção de relações e articulações. Tal como em Laclau e Mouffe, a potência deslocadora da política não está na afirmação de si, mas na rearticulação entre elementos, que gera desidentificações e dá margem ao surgimento de algo efetivamente contestador.
\end{abstract}

\title{
A produção de relatos de si e as cenas de interpelação em Judith Butler
}

Aos conceitos de articulação e desidentificação, advogados, respectivamente, por Laclau e Mouffe e Rancière, gostaríamos de acrescentar, em nosso terceiro passo teórico, a discussão de Judith Butler sobre desconstrução. De forma semelhante a esses três autores, Butler é uma autora que discute a centralidade do processo de desmontagem do sujeito na sua própria configuração. Butler constrói sua abordagem com base em um tenso debate com a obra de Foucault, avaliando as relações de poder e a contingência a atravessar processos de subjetivação. Como bem pontua Salih (2012), a obra de Butler é toda atravessada por um foco na formação do sujeito, desde a publicação de Subjetcts of Desire, em 1987:

O 'sujeito' de Butler não é um indivíduo, mas uma estrutura linguística em formação. A 'sujeitividade' ['subjecthood'] não é um dado, e, uma vez que o sujeito está sempre envolvido num processo de devir sem fim, é possível reassumir ou repetir a sujeitidade de diferentes maneiras (p. 11).

Assim, Butler não busca a identidade, ou mesmo a estabilidade de uma narrativa construída. Sua teoria enfoca a indeterminação e a instabilidade dos processos de subjetivação, que são profundamente marcados por desconstruções ao mesmo tempo em que as encetam. 
Essa discussão fica mais clara em Gender Trouble (1990), quando Butler aprofunda sua discussão sobre a processualidade do sujeito, para colocar em xeque a própria existência da categoria mulher. Na visão da autora, identidades não deveriam ser pensadas como substantivos ou como adjetivos, mas derivam da própria ação. Mulher não é um atributo, mas a consequência de ações, sendo gerada por elas. Daí a centralidade dos performativos em Butler: é na ação que se constrói aquilo que supostamente age.

Fica claro, portanto, que a ação em Butler não é uma mera criação individual. O sujeito está enredado em teias de significação e poder, que atravessam sua agência. É ao performar tais textos - ao citá-los - continuadamente, que os sujeitos os desconstroem e os ressignificam. É na ação que as estruturas se manifestam e são deslocadas. O diálogo de Butler, neste ponto é com a crítica que Derrida faz a Austin: para Derrida, ao invés de funcionar devido às intenções de um/a falante, os performativos funcionam porque encarnam formas linguísticas convencionais que já existiam antes da/o falante usá-las. Dessa forma, os performativos funcionam, e a linguagem em geral funciona, porque podemos (re)citá-los/a (BORBA, 2014, p. 464).

Butler mobiliza, via Derrida, a ideia de iterabilidade, para defender que os signos, quando citados, são inseridos em outros contextos e, por tanto, deslocados. É na citação continuada que os significados, os sujeitos e o mundo se transformam ao longo da ação. Nesse sentido, a subversão vem da desconstrução gerada na reprodução deslocadora do que existe.

Em obras mais recentes, Butler $(2015 ; 2011)$ tem procurado desdobrar essas ideias para pensar as implicações políticas dos relatos de si. Na visão dela, dizer de si é, antes de tudo, um jeito de encontrar o outro, na medida em que gera deslocamentos e desconstrói o próprio lugar estabelecido daquele que fala. Em diálogo com Foucault, Butler entende os relatos de si como um ato de colocar-se diante de um outro que nos interpela; um exercício de despossessão na linguagem: oferecer-lhe uma narrativa em que a autoridade do eu "deve dar lugar à perspectiva e à temporalidade de um conjunto de normas que contesta a singularidade de minha história" (2015, p. 52). Assim, o relato de si ganha contornos em uma cena de interpelação na qual se desenvolve uma ética da responsabilidade tanto com relação à veracidade do relato, quanto ao tipo de vínculo que ele pode estabelecer com os interlocutores.

Tem-se portanto, e novamente, uma compreensão dos processos de subjetivação como essencialmente marcados por rupturas, desconstruções e desencaixes, ainda que de uma forma distinta de Rancière, por exemplo. Em Butler, tornar-se sujeito implica capacidade de agir diante de constrangimentos de poder que fluem por meio de posições de sujeito. O sujeito político, enredado em relações discursivas de poder, constitui-se por meio delas e se submete a elas, em uma constante tensão entre operações conectadas e indissociáveis: assujeitamento e emancipação, dominação e passividade; subjugação 
e autonomia; ação e resistência. Ele aparece na confluência entre o ato de narrar-se, as práticas de interlocução e de suas condições e discursos, que tecem linhas de força e lugares de sujeito que a eles impõe nome, pertencimento e ocupação.

\section{A precedência da ação sobre a identidade}

O quarto e último passo conceitual do percurso que desejamos aqui delinear parte de bases teóricas distintas para construir um argumento semelhante. Trata-se da crítica de Patchen Markell às teorias do reconhecimento. Incomodado com o crescimento da ideia de reconhecimento e temeroso da consolidação de uma compreensão da política centrada no choque entre identidades, Markell quer defender, justamente, que lutas por justiça deveriam se pautar pela desconstrução de identidades e pela ruptura com a ideia de que selves sejam narrativas coerentes que se apresentam publicamente.

Em Bound by Recognition, Markell questiona as perspectivas que buscam pensar o reconhecimento como uma forma de valorização de identidades apresentadas a conhecimento público. Ele alega que re-conhecer pode carregar uma conotação de tornar conhecido novamente algo que já é. De acordo com ele, a política do reconhecimento

[...] é em parte, uma resposta à experiência de vulnerabilidade, ao fato de que
nosas identidades são parcialmente moldadas por meio de respostas imprevisíveis
de outras pessoas: é isto que faz com que ser reconhecido pelos outros pareça
tão agudamente importante em primeiro lugar. O problema é que a política
do reconhecimento responde a este fato por meio da demanda de que os outros
reconheçam-nos como quem nós realmente já somos (MARKELL, 2003, p. 14).

Para o autor, tal visão seria equivocada porque aquilo que se supõe ser é mais bem caracterizado como algo que se torna ao longo de um processo político. Selves são sucessões de rupturas que não têm controle sobre os desdobramentos de suas próprias descontinuidades. Dito de outro modo, Markell (2003), tal como Butler, procura defender a precedência da ação sobre a identidade. Em um denso percurso teórico que envolve a Antígona de Sófocles, o legado arendtiano e uma reinterpretação das ideias de Hegel, Markell afirma que a identidade não pré-existe a um processo reivindicatório, mas se configura ao longo dele. A precedência da ação implica que o sujeito não está pronto quando a realiza, mas se manifesta e se reconfigura ao longo dela.

A política se dá na própria configuração desses sujeitos ao longo de suas ações conjuntas para a criação de uma coletividade. Como na trama de Antígona em que cada ação conduz as personagens a rumos inesperados, o processo de formação de sujeitos é atravessado por forças e dinâmicas não plenamente previsíveis ou administráveis. Sujeitos surgem, ao longo de suas ações e esse "aparecer" é político. É nesse sentido que Markell propõe uma mudança da política do reconhecimento para o que chama de política 
do acknowledgment. Diferentemente do reconhecimento que tentaria, na visão de Markell, promover uma afirmação pública de uma autodefinição, o acknowledgment serviria para desconstruir o anseio de selves soberanos, evidenciando a vulnerabilidade, contingência e dimensão relacional do humano.

Acknowledgment é dirigido às condições básicas da existência e da atividade de uma pessoa, incluindo, crucialmente, os limites da 'identidade' como base da ação; limites que emergem de nossa vulnerabilidade constitutiva às reações e respostas imprevisíveis dos outros. Como uma confissão de nossa própria finitude, acknowledgment, nesse sentido, [...] é um tipo de abdicação (MARKELL, 2003, p. 36).

Acknowledgemnt busca preparar os sujeitos para a abertura em vez de pensá-los como projetos. Tal abertura parte do pressuposto de uma decalagem constitutiva. É preciso pensar políticas que evidenciem aos sujeitos sua condição de vulnerabilidade e dependência mútua para que se possa pensar em justiça. Uma agregação de projetos de si promove uma luta por soberania nessa nossa vulnerabilidade ontológica.

Sob esse aspecto, Markell se aproxima novamente de Butler (2015, 2011), uma vez que ela discute a vulnerabilidade, a precariedade e o desamparo como condição comum a todos os indivíduos, destacando o fato de que todos nós estamos submetidos à interpelação e valorização (ou desvalorização) alheia sobre a qual não temos controle. Butler afirma que esquemas normativos e midiáticos de enquadramento contribuem para uma desigual distribuição da precariedade ao estabelecerem aqueles e aquilo que será e não será apreendido e reconhecido como digno de valor. Para ela, os enquadramentos são operações de poder: "não decidem unilateralmente as condições de aparição dos sujeitos e acontecimentos, mas seu objetivo é delimitar a esfera da aparição enquanto tal" (2015, p. 14). Os enquadramentos atuariam, assim, para diferenciar as vidas que podemos apreender e valorizar daquelas que não podemos.

Tal como Butler, Markell parte da aceitação da precariedade do humano para advogar que desconstruir o self e percebê-lo como atravessado pela falha é a base de processos de subjetivação mais emancipatórios do ponto de vista da política. Em Markell, o sujeito político se forma pelo desencaixe gerado na própria luta política, viabilizando formas de ação que levariam a coletividade a perceber a vulnerabilidade do humano.

\section{Uma breve ilustração: os protextos multitudinários}

Resta-nos, todavia, desenvolver uma questão importante. Os quatro passos conceituais de nossa trajetória projetam um arcabouço teórico bastante abstrato. Articulação, desidentificação, desconstrução e precedência da ação sobre a identidade podem ser expressões atraentes, mas qual o seu potencial heurístico? Eles são úteis para pensar a política de uma forma mais concreta? Ou trata-se apenas de conceitos complexos desenvolvidos no hermetismo de pensadores políticos da contemporaneidade? 
Nesta seção, desejamos realizar uma sucinta ilustração, sem qualquer pretensão de análise empírica, do potencial da ideia que atravessa este artigo (e os quatro passos conceituais que mobilizamos para construí-lo). Essa ilustração se volta para protestos multitudinários recentes, como aqueles observados em contextos tão variados como a Islândia, o Egito, os Estados Unidos, a Espanha, a Turquia e o Brasil (CASTELLS, 2013; FOMINAYA, 2014; DELA PORTA, 2015). Diante do caos e da incerteza alimentados por tais manifestações (DOMINGUES, 2014; MENDONÇA et al., 2016), e da força de manifestações individuais nesses processos (BENNETT \& SEGERBERG, 2013; CASTELLS, 2013), tornou-se importante discutir os elementos configuradores de identidades coletivas ao longo desses processos (MENDONÇA, 2015; GERBAUDO, 2015; GERBAUDO \& TRERÉ, 2015; MONTERDE et al. 2015). Pautada na discussão mais tradicional sobre confronto político, e inspirada nas discussões canônicas de Melucci (1996) sobre identidade coletiva, essa literatura busca identificar as condições de tessitura de um "nós", ainda que instável, heterogêneo e plural, a atravessar tais ciclos de protestos. O que permanece subexplorado nessa literatura é o papel da desidentificação, do deslocamento das articulações, da desconstrução de si e da precedência da ação e das relações comunicativas sobre a identidade.

Esses protestos são profundamente desestabilizantes, porque não se ancoram em formas estabelecidas e localizáveis de identificação. Não é possível defini-los como uma luta do proletariado, da classe média, das mulheres, das pessoas LGBT, de coletivos fascistas ou anarquistas. O coletivo que surge nesses protestos não é uma agregação de identificações plurais existentes, mas muito frequentemente, algum tipo de coletividade que não existia antes de sua emergência. Os 99\% do Occupy, os Indignados espanhóis e os manifestantes das Jornadas de Junho de 2013 e 2015 brasileira não são a soma contraditória de grupos, embora frequentemente busquemos pensá-los como tal. Sua novidade e potência desestabilizadora residem no fato de emergirem novos processos de subjetivação em que se questionam, como propõe Rancière, os lugares sociológicos pré-moldados para a ocupação daqueles sujeitos. O sujeito político dessas manifestações é incontrolável e inclassificável, porque opera fora dos cálculos em vigor. Trata-se, ainda nos termos de Rancière, do despontar dos sem-parte, que evidenciam os limites (e a conta mal feita) das ordens vigentes. Evidência essa de natureza estética, na medida em que descortina outras partilhas do sensível passívieis de modelar a experimentação de novos mundos e modos de existência.

A subjetivação política, nos atuais contextos sociopolíticos, não se apoia tanto mais em sujeitos coletivos (como o proletariado, por exemplo), mas também não pode ser pensada como combinação de experiências individuais. Tal processo de subjetivação implica a ação de coletivos que se apoiam sobre indivíduos que almejam e dão forma a outros mundos possíveis. As desidentificações produzem transformações individuais e coletivas: produzem formas de emancipação que não se reduzem à autonomia individual, mas valorizam a produção de relações, cenas e enunciação e articulações entre forças e indivíduos desidentificados de suas designações outorgadas. 
Se nos voltarmos para a discussão de Laclau e Mouffe, fica ainda mais claro que esse processo de desidentificação de que fala Rancière, envolve uma contestação das articulações em voga, que possibilita uma transformação substantiva dos próprios elementos em sua base. Tais protestos criam novas possibilidades de subjetivação, porque criam condições para que relações simbólicas sejam repensadas e transformadas. Vale lembrar que, em Laclau e Mouffe, articulações não são configuradas por elementos pré-existentes, sendo configuradoras dos elementos que se articulam. Nesse sentido, protestos multitudinários contemporâneos abrem oportunidades históricas para que indivíduos se repensem e se redefinam em outras tramas articulatórias. Devolvidos à condição de elementos, eles podem se desencaixar de lugares pré-definidos e isso tem consequências significativas sobre a própria forma da luta.

Entendemos, portanto, que protestos como as Jornadas de Junho não foram um simples encontro de insatisfações diversas. Sua natureza acontecimental (MENDONÇA et al., 2016) está ligada ao fato de tais protestos serem atravessados por processos nos quais os próprios sujeitos se repensam, desencaixam-se e desconstroem-se. Como Butler e Markell argumentam, embora por caminhos diversos, a ação tem precedência sobre a identidade. Os atores em protesto não estavam pré-estabelecidos à luta que conduziram, mas foram se moldando, de forma precária, vulnerável e incerta ao longo dos desdobramentos, também precários e incertos de suas ações.

Entender manifestações multitudinárias contemporâneas por essas lentes ajuda a pensar não os mínimos denominadores comuns a atravessarem a miríade contraditória de sujeitos ali presentes, mas a potência deslocadora de eventos dessa natureza, que fomentam desencaixes e rearticulações profundamente transformadores. Tais protestos tendem a estabelecer condições para efetivos processos de subjetivação, gerando rupturas não apenas na forma como sujeitos se entendem, mas também na dinâmica mais ampla das relações sociais. Desidentificações e desconstruções dessa natureza são profundamente políticas, porque colocam novos sujeitos em cena e, ao fazê-lo, afetam os jogos de poder vigente, as estruturas estabelecidas e as articulações em voga.

Ao mesmo tempo, tais desidentificações e desconstruções são estéticas porque são experimentações: marcam uma recusa a identidades que aprisionam, e uma busca pelos territórios existenciais não sujeitos a um princípio hegemônico. A produção do "entre" via criação de articulações, de passagens e dos trânsitos entre linguagens, ideias e sujeitos cria condições para a transformação e a experimentação questionadora das relações de poder que produzem subjetividade e diferença.

Assim, a busca pela ideia de identidade coletiva nos protestos multitudinários contemporâneos não pode negligenciar a centralidade dos desencaixes gerados por esses protestos. Mais do que ações promovidas por uma pluralidade de atores, tais protestos são desencadeadores de processos de subjetivação, alimentando a configuração histórica de novos sujeitos. Sujeitos esses que não pré-existiam à luta em que se inserem, e cuja 
capacidade de mudança social (não necessariamente em direções emancipatórias, que fique claro) advém justamente dessa questão. Esses protestos lançam luz sobre os desencaixes atuais por meio dos quais novos sujeitos ocupam a cena pública e criam agenciamentos expressivos e comunicativos que deslocam as possibilidades de ser e existir.

Angela Cristina Salgueiro Marques é doutora pela UFMG e professora do Programa de Pós-graduação em Comunicação Social da UFMG.

angelasalgueiro@gmail.com

Ricardo Fabrino Mendonça é doutor pela UFMG e professor do Programa de Pós-graduação em Ciência Política da UFMG.

ricardofabrino@hotmail.com

\section{Referências}

BENNETT, L; SEGERBERG, A. The logic of connective action. New York: Cambridge University Press, 2013.

BORBA, R. A linguagem importa? Sobre performance, performatividade e peregrinações conceituais. Cad. Pagu [online]. 2014, n. 43, p. 441-474.

BUTLER, J. Quadros de guerra: quando a vida é passível de luto? Rio de Janeiro: Civilização Brasileira, 2015.

Gender trouble: feminism and the subversion of identity. New York: Routledge, 1999.

Relatar a si mesmo. Belo Horizonte: Autêntica, 2015.

2011

Vida precária. Contemporânea, Revista de Sociologia da UFSCar. São Carlos, n. 1, p. 13-33,

Subjects of desire. Columbia University Press, 1987.

CASTELLS, M. Redes de indignação e esperança. Rio de Janeiro: Zahar, 2013.

DELLA PORTA, D. Social movements in times of austerity: Bringing Capitalism Back Into Protest Analysis. Cambridge: Polity Press, 2015.

DOMINGUES, J. M. O Brasil entre o presente e o futuro. Rio De Janeiro: Mauad, 2015.

FJELD, A.; TASSIN, E. Subjectivation et désidentification politiques: dialogue à partir d'Arendt et de Rancière. Ciencia Política, v. 10, n. 19, p. 193-223, 2015.

FOMINAYA,C. F. Social movements and globalization: how protests, occupations and uprisings are changing the world. Palgrave, 2014.

FOUCAULT, M. A ordem do discurso: aula inaugural no Collège de France, pronunciada em 2 de dezembro de 1970. São Paulo: Loyola, 2009.

Les techniques de soi. In: DEFERT, D.; EWALD, F.; LAGRANGE, J. Dits et écrits. 1954-1988.

Paris: Gallimard, 1984. 
O sujeito e o poder. In: RABINOW, P.; DREYFUS, H. (Ed.). M. Foucault: uma trajetória filosófica para além do estruturalismo e da hermenêutica. Rio de Janeiro: Rorense Universitária, 1995.

GERBAUDO, P. Protest avatars as memetic signifiers: political profile pictures and the construction of collective identity on social media in the 2011 protest wave. Information, Communication \& Society, v. 18, n. 8, p. 916-929, 2015.

GERBAUDO, P; TRERÉ, E. In search of the 'we' of social media activism: introduction to the special issue on social media and protest identities. Information, Communication \& Society, v. 18, n. 8 , p. $865-871,2015$.

LACLAU, E.; MOUFFE, C. Hegemony and socialist strategy: towards a radical democratic politics. London; New York, NY: Verso, 2001.

LELO, T. V.; MARQUES, A. Democracia e pós-democracia no pensamento político de Jacques Rancière a partir das noções de igualdade, ética e dissenso. Revista Brasileira de Ciência Política (Impresso), p. 349-374, 2014

MARKELL, P. Bound by recognition. Princeton: Princeton University Press, 2003.

MELUCCl, A. Challenging codes: collective action in the information age. Cambridge: Cambridge University Press, 1996.

MENDONÇA, R. F. Singularidade e identidade nas manifestações de 2013. 39 Encontro Anual da Anpocs, realizado em Caxambu entre 26 e 30 de outubro de 2015.

MENDONÇA, R. F.; ERCAN, S.; OZGUC, U; REIS, S.; SIMÕES, P. Understanding protests as 'events': the symbolic struggles in 2013 protests in Turkey and Brazil. 24${ }^{\text {. }}$. Encontro da IPSA, Poznan, 23-28 de jul. de 2016.

MONTERDE, A; CALLEJA-LÓPEZ, A.; AGUILERA, M.; BARANDIARAN, X.; POSTILL, J. Multitudinous identities: a qualitative and network analysis of the $15 \mathrm{M}$ collective identity. Information, Communication \& Society, v. 18, n. 8, p. 930-950, 2015.

RANCIÈRE, J. La Mésentente: politique et philosophie. Paris: Galilée, 1995.

Aux bords du politique. Paris: Gallimard, 2004.

Against an ebbing tide: An interview with Jacques Rancière. Reading Rancière: critical dissensus, ed. Paul Bowman and Richard Stamp. London: Continuum, 2011.

Does democracy means something? In: Dissensus: on politics and aesthetics. Edited and transleted by Steven Corcoran. London: Continuum, p. 45-61, 2010.

El método de la igualdad: conversaciones com Laurent Jeanpierre y Dork Zabunyan. Buenos Aires: Claves, 2014.

SALIH, S. Judith Butler e a teoria queer. Belo Horizonte: Autêntica, 2012.

Artigo recebido em 05 de julho e aprovado em 23 de agosto de 2017. 